\title{
Redundant internal coordinates, compliance constants and non-bonded interactions - some new insights
}

\author{
MOUMITA MAJUMDER and SADASIVAM MANOGARAN* \\ Department of Chemistry, Indian Institute of Technology Kanpur, Kanpur 208 016, India \\ e-mail: sm@iitk.ac.in
}

MS received 21 February 2012; revised 8 July 2012; accepted 20 July 2012

\begin{abstract}
A long standing problem in normal mode analysis is identifying the right internal coordinates given only the cartesian coordinates, the masses of the atoms and the cartesian force constants without using any other additional chemical information. A possible solution is suggested here as drawing the normal modes obtained from the mass weighted cartesian force constant matrix and identifying the correct bonds and angles from the normal mode pictures. If chosen properly, the internal coordinates will have minimum mixing in the normal mode representation. This can in principle lead to an automation algorithm. A complete basis of internal coordinates is defined as the minimum number of valence internal coordinates that describe all the normal modes as completely as possible. It was shown in the literature that the relaxed force constants could be used as a measure of bond order in all atom-atom distance coordinates. Some of the bonded and non-bonded atom pairs can have similar values of the relaxed force constants and hence to use the relaxed force constant as a measure of bond order we need to separate the bonded pairs from the non-bonded ones. This needs extra chemical information of which pairs are bonded. The new definition of complete basis of non-redundant valence internal coordinates helps to identify the bonded pairs effectively without extra information. The hydrogen bonded water clusters $\left(\mathrm{H}_{2} \mathrm{O}\right)_{\mathrm{n}}, \mathrm{n}=2-6$, methane dimer and methane-water complex are used as examples to verify that the relaxed force constants of bonded pairs are indeed a measure of bond order.
\end{abstract}

Keywords. Redundant internal coordinates; compliance constants; non-bonded interactions; normal modes; complete basis.

\section{Introduction}

The internal coordinates are used in the vibrational problem in order to visualize the normal modes in terms of stretching, bending, etc. Also, the internal coordinate force constants could be studied in order to understand the similarities and differences between two structurally related molecules. The force constants when they are unknown could be transferred from related molecules if internal coordinates are used. However, for many molecules the number of needed internal coordinates of a molecule is more than the number of vibrational degrees of freedom which is $3 \mathrm{~N}-6$ for non-linear and $3 \mathrm{~N}-5$ for linear molecules of $\mathrm{N}$ atoms. Since the number of internal coordinates are more than the vibrational degrees of freedom, it was considered that they are redundant. Redundancy and their removal was considered by several authors. ${ }^{1-3}$ If we can find a unique and

*For correspondence satisfactory complete valence internal coordinate set, given the cartesian coordinates and masses of the atoms and the cartesian hessian of a molecule with out any additional information like covalent radii, it will resolve the ambiguity in the force fields obtained by using different sets of internal coordinates. If we can automate this algorithm, a long standing problem in normal mode analysis will be solved. Here, we make a beginning for such an attempt. The proposed solution is to do the normal mode analysis in mass weighted cartesian coordinates and draw the normal mode pictures. The normal mode pictures indicate which bonds and angles are the most suitable ones for the complete representation of normal modes. The minimum number of valence internal coordinates needed to describe all the normal modes as completely as possible form the unique, most suitable valence internal coordinates. If there is a problem in the uniqueness, the one which gives the minimum mixing of internal coordinates in the normal mode representation is the one which will give the most satisfactory solution. This is done with out any additional information like covalent radii to identify the bonds 
in the molecule, which is not very satisfactory when unusual bond lengths occur between bonded pairs. Also in cases like [1,1,1]-propellane, the covalent radii infer the central CC as a normal covalent bonded pair while the wave function analysis indicates low electron density between the central $\mathrm{CC}$ atom pair indicating that it is not a normal covalent bond as described later in the manuscript. The proposed method appears to overcome these difficulties. In principle, this method could be automated.

About 10 years ago, Grunenberg has shown that the relaxed force constants, the inverse of the diagonal compliance matrix elements are a measure of bond order, ${ }^{4-7}$ even in the case of weak-interactions. ${ }^{8}$ However, it was pointed out that when using all atom-atom distances for normal mode analysis, some of the bonded atom pairs and non-bonded ones could have similar values of relaxed force constants and hence unless we know which pairs of atoms are really bonded, we can not effectively use the compliance constants as a measure of bond order. ${ }^{9,10}$ This needs additional chemical information of which pairs are bonded and which are non-bonded. The new definition of the complete set of valence internal coordinates leads to the identification of bonded atom pairs in a molecule without any additional information. Since unique identification of bonds are possible, the difficulty disappears and we know for which pair of atoms the inverse compliance constants could be used as a measure of bond order. Also it is explicitly shown that only when we use the correct theory with reasonably large basis set, we get the right correspondence between the relaxed force constant and bond order.

\section{Results and discussion}

The real (experimental) force field of a molecule contains information about the forces between all atoms in the molecule and we need a complete basis set to represent the force field. The force field of an $\mathrm{N}$-atomic molecule requires $3 \mathrm{~N}-6$ (non-linear) or $3 \mathrm{~N}-5$ (linear) coordinates in normal coordinate space. Normal coordinates are mathematical construct obtained by forming linear combination of cartesian, mass weighted cartesian, all possible distance coordinates or valence internal coordinates. 'To represent an unknown function as a linear combination of known functions, the known functions should form a complete basis. ${ }^{11}$ When each normal coordinate is written as a linear combination of known coordinates, it is important that the known coordinates form a complete basis set'. In cartesian or mass weighted cartesian we need $3 \mathrm{~N}$ coordinates (not $3 \mathrm{~N}-6$ or $3 \mathrm{~N}-5$ ) to represent each normal mode because these $3 \mathrm{~N}$ coordinates form a complete basis. In distance only coordinates, we need $\mathrm{N}(\mathrm{N}-1) / 2$ coordinates, to form a complete basis. We want to emphasize that it is not true that we need only $3 \mathrm{~N}-6$ or $3 \mathrm{~N}-5$ valence internal coordinates to form the complete basis. It depends on the symmetry and the nature of the molecule.

For an $\mathrm{N}$-atomic molecule, if the $\mathrm{N}$ masses, $3 \mathrm{~N}$ cartesian coordinates and $(3 \mathrm{~N} \times 3 \mathrm{~N})$ cartesian force constants are given, how do we decide the most suitable internal coordinates to represent the normal modes without using additional chemical information? It appears that one of the solutions is to do a normal mode analysis in mass weighted cartesian coordinates and draw the normal modes. The normal mode pictures should tell us which bond stretchings, valence angle bendings, out of plane bendings and torsions are most appropriate to represent the normal modes. When the internal coordinates are chosen properly, they will have minimum mixing in the description of the normal modes. For example in water, $\mathrm{OH}_{1}, \mathrm{OH}_{2}, \mathrm{H}_{1} \mathrm{OH}_{2}$, $\mathrm{H}_{1} \mathrm{H}_{2}, \mathrm{OH}_{1} \mathrm{H}_{2}, \mathrm{OH}_{2} \mathrm{H}_{1}$ are all valid internal coordinates. The normal modes of water are symmetric stretch, antisymmetric stretch and bending. The three coordinates $\mathrm{OH}_{1}, \mathrm{OH}_{2}$ and $\mathrm{H}_{1} \mathrm{OH}_{2}$ completely describe the three normal modes and hence form a complete basis. In the same way, we could choose the $6 \mathrm{CH}$ and $6 \mathrm{CC}$ as the stretching coordinates in benzene. We define the minimum number of valence internal coordinates that describe the normal modes as completely as possible as a 'complete basis'. Any coordinate more than the required minimum is extra in the complete basis set and not required. For example in water, if we add $\mathrm{H}_{1} \mathrm{H}_{2}$ as additional coordinate with $\mathrm{OH}_{1}, \mathrm{OH}_{2}$ and $\mathrm{H}_{1} \mathrm{OH}_{2}$, then $\mathrm{H}_{1} \mathrm{H}_{2}$ is extra in the complete basis. In the same way, in $[1,1,1]$ propellene the central $\mathrm{C}-\mathrm{C}$ bond and associated angles are excess and not required in the complete basis set of valence internal coordinates. ${ }^{12,13}$ In $[1,1,1]$ propellane, one mode in simulation appears as central $\mathrm{C}-\mathrm{C}$ bond stretch. But actually this is a $\mathrm{C}-\mathrm{C}-\mathrm{C}$ bend if we carefully look at the mode. $[1,1,1]$ propellane can be thought of as three $\mathrm{CH}_{4}$ molecules (actually $\mathrm{H}_{2} \mathrm{CC}_{2}$ groups) joined together at the central $\mathrm{C}-\mathrm{C}$ bond. The fact that in methane we have only $\mathrm{HCH}$ bendings and not $\mathrm{HH}$ stretch, will clarify that this mode is not the central $\mathrm{C}-\mathrm{C}$ stretch but $\mathrm{CCC}$ bend.

The validity of the complete basis set concept can be appreciated by the methane example given in reference. ${ }^{14}$ Here $4 \mathrm{C}-\mathrm{H}$ and $5 \mathrm{HCH}$ angles $(3 \times 5-6=9)$ are used for the normal mode analysis with the result of having two different force constant values for the equivalent $\mathrm{HCH}$ angles which can not be used in any sensible 
way. The complete set should include all the six $\mathrm{HCH}$ angles. The force constants reported in table 2 of reference 9 are for distance only coordinates given for different cut-off distances. Only when all the distances are included in the basis, the set forms a complete set and hence gives the correct force constant values. Different cut-off distances form an 'incomplete set' of coordinates and hence give incorrect force constants. To support our argument, we quote from Reviews in computational chemistry. ${ }^{15}$ 'Using redundant coordinates circumvents (1) destroying the symmetry of the system ... (2) and using an incomplete set of 3N-6 internal coordinates that does not fully span the vibrational space. Therefore, the recommendation is that for more than four atoms one should always use the redundant internal coordinates to evaluate the generalized normal mode frequencies.'

In cases where no explicit atom exists at one end for stretching like in ferrocene, $\mathrm{LiC}_{5} \mathrm{H}_{5}$, etc. dummy atom(s) representation used in reference 16 will solve the problem of choosing the right internal coordinates. For example, having a dummy atom in the centre of the $\mathrm{C}_{5} \mathrm{H}_{5}^{(-)}$ring, the ring - $\mathrm{Li}$ stretch could be added as Li-D (D for dummy atom) bond in the internal coordinates. The coordinates of the dummy atom and the chain rule of differentiation are used to get the Wilson's $\mathrm{B}$ matrix and normal mode analysis is done as explained in reference 16.

Let us try to analyse the meaning of 'redundancy' in the redundant internal coordinates more carefully. Let us take the three angles in $\mathrm{BF}_{3}$, which are part of the complete valence internal coordinate basis. Since all the three angles are in the required minimum needed to describe all the normal modes, the 'redundancy' cannot mean that any two are sufficient and the third is redundant. It could only mean that the three linear combinations of the three angles needed to describe the normal modes completely has one 'null' or 'redundant' coordinate $a_{1}+a_{2}+a_{3}=0$ which could be omitted in the normal mode analysis. When a linear combination of internal coordinates give a 'null' coordinate, the 'null' coordinate gives zeroes along the rows and columns of $\mathrm{G}$ matrix ${ }^{17,18}$ and hence the corresponding zero rows and columns of $\mathrm{G}$ and $\mathrm{F}$ matrices could be omitted during normal mode analysis. ${ }^{19}$ If a linear combination of internal coordinates vanishes, the corresponding $G$ matrix elements also vanish was proved by Califano. ${ }^{18}$ $a_{1}+a_{2}+a_{3}=0$ does not mean the sum of $a_{1}$ and $a_{2}$ will give $a_{3} \cdot a_{1}, a_{2}$ and $a_{3}$ represent different physical regions in $\mathrm{BF}_{3}$ and sum of any two regions will not give the third. The same way in $\mathrm{CH}_{3} \mathrm{~F}$, consider $S_{1}=$ $1 / \sqrt{3}\left(a_{1}+a_{2}+a_{3}\right)$ and $S_{2}=1 / \sqrt{3}\left(b_{1}+b_{2}+b_{3}\right)$ with $\mathrm{S}_{1}+\mathrm{S}_{2}=0$. This means that the linear combinations of the six angles give one 'null' coordinate which is redundant and could be omitted. The other 5 linear combinations can describe all the normal modes completely. It does not mean $S_{2}$ can be replaced by $S_{1}$ as explained in reference 13. The situation is similar in other molecules where we need more than $3 \mathrm{~N}-6$ (or $3 \mathrm{~N}-5$ ) in the set of the minimum required valence internal coordinates to form the complete basis. The 'redundant' internal coordinates mean that, the minimum number of internal coordinates needed to describe all the normal modes completely will give extra or redundant 'null' coordinate linear combinations, in addition to $3 \mathrm{~N}-6$ (or $3 \mathrm{~N}-5$ ) linear combinations (in which some of the coefficients could be zero) which are enough to describe all the normal modes completely. The null coordinates could be obtained by diagonalizing the $\mathrm{G}$ matrix and taking the eigen vectors corresponding to the zero eigen values. ${ }^{13}$ 'Redundancy' does not mean that any $3 \mathrm{~N}-6$ (or $3 \mathrm{~N}-5$ ) valence internal coordinates in the complete basis are enough to describe all the normal modes completely and the rest in the complete basis are redundant and hence not required in the complete description of all the normal modes. Some readers may get the impression that the redundancy is tied up with $\mathrm{G}$ matrix and hence to internal coordinates although it is more general. This is because we are working with internal coordinates as basis and the idea can be extended to other coordinate systems.

This new definition of complete valence internal coordinates clearly defines the bonds in a given molecule, even when it is a weakly bonded cluster like hydrogen bonded water dimer, trimer, etc. or van der Waals complex like methane dimer. As long as we use the complete set of valence internal coordinates, we know the bonded pairs and hence we know for which pairs the relaxed force constants could be used as a measure of bond order. Since the coordinates in excess of the minimum required coordinates to form a complete basis set, are not required in the description of normal modes, their compliance constants are not necessarily a measure of bond order. Only compliance constants for the bonds in the complete basis set of valence internal coordinates-which is the minimum valence internal coordinates that describe all the normal modes completely — could be used as a measure of bond order. It should be made clear that this complete basis of valence internal coordinates can be more than $3 N-6$.

In the case of water molecule, $\mathrm{O}-\mathrm{H}_{1}, \mathrm{O}-\mathrm{H}_{2}$ and $\mathrm{H}_{1}-$ $\mathrm{H}_{2}$ represent the basis set of all distances and $\mathrm{O}-\mathrm{H}_{1}$, $\mathrm{O}-\mathrm{H}_{2}$ and $\angle \mathrm{H}_{1} \mathrm{OH}_{2}$ represent the basis set in valence internal coordinates. Since $\mathrm{H}-\mathrm{H}$ is not a coordinate in the basis set of complete valence internal coordinates, 
$\mathrm{H}_{1}-\mathrm{H}_{2}$ compliance constant is not necessarily a measure of bond order. Again in triatomic molecule A-B$\mathrm{C}$, the valence internal coordinate basis does not include the $\mathrm{A}-\mathrm{C}$ bond. In all the molecules the non-bonded pairs that are not part of the basis in valence internal coordinates are in excess of the required minimum. Hence their relaxed force constants are not necessarily a measure of bond order.

When we use valence internal coordinates for a dimer, there has to be one or more connecting bonds between the monomers which will necessarily be included in the basis set along with the associated angles. The compliance constants of these bonds which may represent hydrogen bonds as in adenine-thymine or guanine-cytosine base pairs or other weak interactions as in methane dimer could be used as a measure of bond order. This could be extended to larger clusters.
Water clusters contain several hydrogen bonds of varying strength. This large variation could be used to test the relation between bond orders obtained from the $\mathrm{NBO}$ analysis ${ }^{20}$ of the wave functions and the relaxed force constants obtained from the normal mode analysis using valence internal coordinates as the basis. For the covalent $\mathrm{O}-\mathrm{H}$, the linear correlation is excellent as expected and so is not shown here. For the hydrogen bond $\mathrm{O} \cdots \mathrm{H}$, the correlation is very good. Noting that the very low bond orders involved here have large uncertainty in their calculation from the wave functions, the observed correlation in figure 1 is very good to justify that the relaxed force constants are suitable to characterize hydrogen bonds. The same way, the relaxed force constants obtained for methane dimer, methane-water cluster and water dimer are used to characterize weak and strong non-bonded interactions as shown in table 1 .

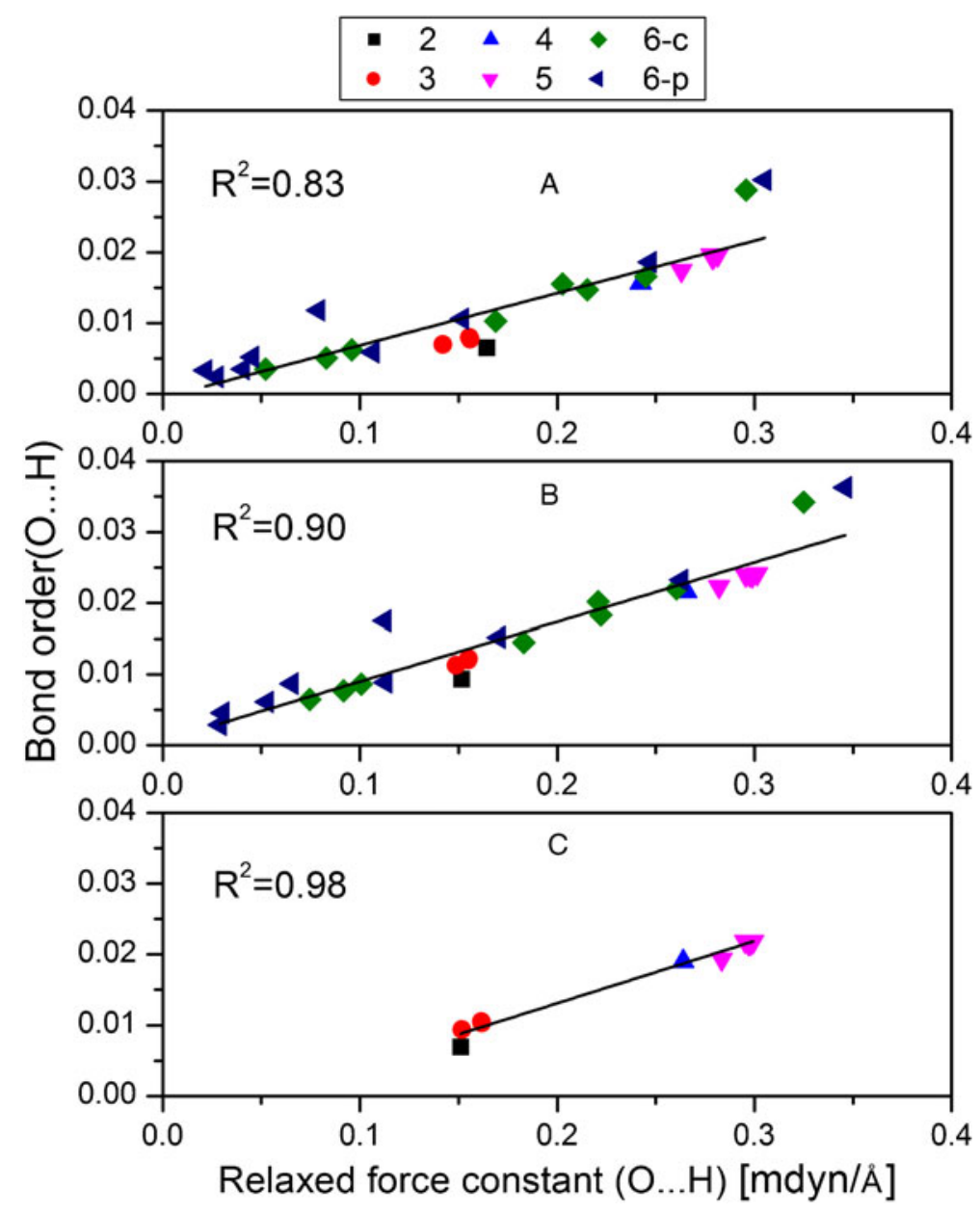

Figure 1. Correlation plots between relaxed force constants $C_{i i}^{-1}$ in (mdyn/ $/$ ) and bond orders (obtained from NBO analysis) for various water clusters $\left(\mathrm{H}_{2} \mathrm{O}\right)_{\mathrm{n}}, \mathrm{n}=2-6$. $\mathrm{A}, \mathrm{B}$ and $\mathrm{C}$ correspond to the correlation plots obtained at MP2/6-311++G**, MP2/aug-cc-pVDZ and MP2/aug-cc-pVTZ levels of theory, respectively. 
Table 1. Optimized A $\cdots X$ distances, their relaxed force constants $\left(C_{i i}^{-1}\right.$ in mdyn/ $\AA$ ) and their binding energies (BSSE corrected) for methane dimer, methane-water complex and water dimer at the MP2/aug-cc-pVDZ and MP2/aug-cc-pVTZ levels of theory, respectively.

\begin{tabular}{lccccccc}
\hline & \multicolumn{3}{c}{ MP2/aug-cc-pVDZ } & & \multicolumn{3}{c}{ MP2/aug-cc-pVTZ } \\
\cline { 2 - 4 } & $\mathrm{R}_{\mathrm{A} \cdots \mathrm{x}}^{\mathrm{a}}$ & $\mathrm{C}_{\mathrm{ii}}^{-1 \mathrm{~b}}$ & $\mathrm{BE}^{\mathrm{c}}$ & & $\mathrm{R}_{\mathrm{A} \cdots \mathrm{x}}^{\mathrm{a}}$ & $\mathrm{C}_{\mathrm{ii}}^{-1 \mathrm{~b}}$ & $\mathrm{BE}^{\mathrm{c}}$ \\
\hline $\mathrm{H}_{4} \mathrm{C} \cdots \mathrm{CH}_{4}$ & 3.582 & 0.0310 & -0.95 & & 3.584 & 0.0262 & -0.60 \\
$\mathrm{H}_{4} \mathrm{C} \cdots \mathrm{HOH}$ & 2.566 & 0.0357 & -1.36 & & 2.526 & 0.0397 & -1.17 \\
$\mathrm{H}_{2} \mathrm{O} \cdots \mathrm{HOH}$ & 1.953 & 0.1516 & -5.30 & & 1.945 & 0.1511 & -5.22 \\
\hline
\end{tabular}

${ }^{\mathrm{a}}$ Distances are reported in $\AA$.

${ }^{\mathrm{b}}$ Relaxed force constants are reported in $\mathrm{mdyn} / \mathrm{A}$.

${ }^{\mathrm{c}}$ Binding energy (BE) are reported in $\mathrm{Kcal} / \mathrm{mol}$.

As observed by the others, the hydrogen bond strength should increase gradually from the dimer to the trimer to the tetramer due to cooperative effects. ${ }^{21,22}$ However in MP2/6-311++ $\mathrm{G}^{* *}$ this trend is not observed. Trimer $\left(\mathrm{C}_{\mathrm{ii}}^{-1}=0.1555,0.1559\right.$ and 0.1420$)$ is weaker than dimer $\left(\mathrm{C}_{\mathrm{ii}}^{-1}=0.1644\right)$. When we change the basis set from 6-311++G** to aug-cc-pVDZ, among three bonds of the trimer, two $\left(\mathrm{C}_{\mathrm{ii}}^{-1}=0.1551,0.1549\right)$ show higher and one $\left(\mathrm{C}_{\mathrm{ii}}^{-1}=0.1488\right)$ shows lower value than the dimer $\left(\mathrm{C}_{\mathrm{ii}}^{-1}=0.1516\right)$. Changing the basis set to aug-cc-pVTZ produces the correct order: dimer $\left(\mathrm{C}_{\mathrm{ii}}^{-1}=0.1511\right)<\operatorname{trimer}\left(\mathrm{C}_{\mathrm{ii}}^{-1}=0.1619,0.1617\right.$ and $0.1517)<$ tetramer $\left(\mathrm{C}_{\mathrm{ii}}^{-1}=0.2639\right)<\operatorname{pentamer}\left(\mathrm{C}_{\mathrm{ii}}^{-1}=\right.$ $0.2835,0.2954,0.2971,0.2993$ and 0.2982$)$. Our computer resources did not permit the calculation beyond the pentamer at this level. The optimized geometries of different water clusters under investigation are illustrated in figure 2 . The complete data for water clusters $\left[\left(\mathrm{H}_{2} \mathrm{O}\right)_{n}, \mathrm{n}=2,6\right]$ are given in table 2. This shows clearly that we have to use the appropriate method and a reasonably large basis set to characterize the force constants in electronic structure calculation. Then only the force constants will agree with the expected (for example based on experimental values) values and the compliance constant calculated for the bond is a measure of true bond order. All geometry optimizations and calculations of the cartesian force constant are performed using Gaussian03 suite of programs. ${ }^{23}$ The compliance constants are obtained using a modified version of UMAT program obtained from QCPE. ${ }^{19}$

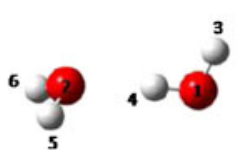

(a)

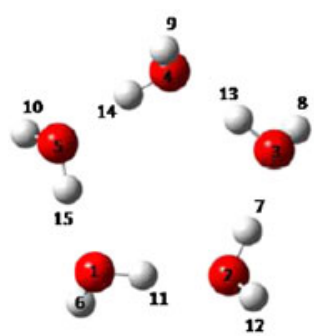

(d)

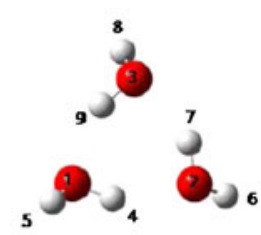

(b)

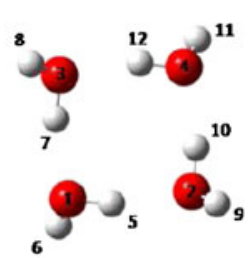

(c)

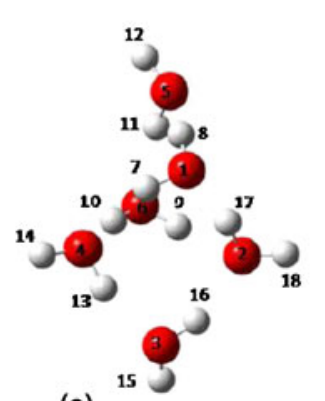

(e)

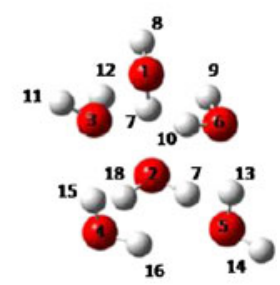

(f)

Figure 2. Optimized structures of various water clusters, $\left(\mathrm{H}_{2} \mathrm{O}\right)_{n}$ ( $\mathrm{n}=$ 2-6). (a) Dimer, (b) trimer, (c) tetramer, (d) pentamer, (e) hexamer-cage and (f) hexamer-prism. 
Table 2. Optimized bond distances, relaxed force constants $\left(\mathrm{C}_{\mathrm{ii}}^{-1}\right.$ in mdyn/ $\mathrm{\AA}$ ) and bond orders (obtained from NBO analysis) for water clusters, $\left(\mathrm{H}_{2} \mathrm{O}\right)_{\mathrm{n}}(\mathrm{n}=2-6)$ at MP2/6-311++G**, MP2/aug-cc-pVDZ and MP2/aug-cc-pVTZ levels of theory, respectively. The atom numbers as given in figure 2.

\begin{tabular}{|c|c|c|c|c|c|c|c|c|c|}
\hline \multirow[b]{2}{*}{ Bond } & \multicolumn{3}{|c|}{$\mathrm{MP} 2 / 6-311++\mathrm{G}^{* *}$} & \multicolumn{3}{|c|}{ MP2/aug-cc-pVDZ } & \multicolumn{3}{|c|}{ MP2/aug-cc-pVTZ } \\
\hline & $\begin{array}{c}\mathrm{R}_{\mathrm{X} \cdots \mathrm{H}} \\
(\AA)\end{array}$ & $\begin{array}{c}\mathrm{C}_{\mathrm{ii}}^{-1} \\
(\mathrm{mdyn} / \AA)\end{array}$ & Bond order & $\begin{array}{c}\mathrm{R}_{\mathrm{X} \cdots \mathrm{H}} \\
(\AA)\end{array}$ & $\begin{array}{c}\mathrm{C}_{\mathrm{ii}}^{-1} \\
(\mathrm{mdyn} / \AA)\end{array}$ & Bond order & $\begin{array}{c}\mathrm{R}_{\mathrm{X} \cdots \mathrm{H}} \\
(\AA)\end{array}$ & $\begin{array}{c}\mathrm{C}_{\mathrm{ii}}^{-1} \\
(\mathrm{mdyn} / \AA)\end{array}$ & Bond order \\
\hline$(\text { water })_{2}$ & & & & & & & & & \\
\hline $\begin{array}{l}\mathrm{O}_{2} \cdots \mathrm{H}_{4} \\
\text { (water) })_{3}\end{array}$ & 1.949 & 0.1644 & 0.0065 & 1.953 & 0.1516 & 0.0093 & 1.945 & 0.1511 & 0.0069 \\
\hline $\mathrm{O}_{1} \cdots \mathrm{H}_{9}$ & 1.918 & 0.1555 & 0.0080 & 1.908 & 0.1551 & 0.0122 & 1.892 & 0.1619 & 0.0103 \\
\hline $\mathrm{O}_{2} \cdots \mathrm{H}_{4}$ & 1.916 & 0.1559 & 0.0077 & 1.907 & 0.1549 & 0.0120 & 1.892 & 0.1617 & 0.0105 \\
\hline $\begin{array}{l}\mathrm{O}_{3} \cdots \mathrm{H}_{7} \\
\text { (water) })_{4}\end{array}$ & 1.944 & 0.1420 & 0.0070 & 1.922 & 0.1488 & 0.0113 & 1.911 & 0.1517 & 0.0094 \\
\hline $\mathrm{O}_{1} \cdots \mathrm{H}_{7}$ & 1.794 & 0.2424 & 0.0157 & 1.777 & 0.2654 & 0.0216 & 1.765 & 0.2639 & 0.0190 \\
\hline $\mathrm{O}_{2} \cdots \mathrm{H}_{5}$ & 1.794 & 0.2424 & 0.0157 & 1.777 & 0.2654 & 0.0216 & 1.765 & 0.2639 & 0.0190 \\
\hline $\mathrm{O}_{3} \cdots \mathrm{H}_{12}$ & 1.794 & 0.2424 & 0.0157 & 1.777 & 0.2654 & 0.0216 & 1.765 & 0.2639 & 0.0190 \\
\hline $\begin{array}{l}\mathrm{O}_{4} \cdots \mathrm{H}_{10} \\
\text { (water) })_{5}\end{array}$ & 1.794 & 0.2424 & 0.0157 & 1.777 & 0.2654 & 0.0216 & 1.765 & 0.2639 & 0.0190 \\
\hline $\mathrm{O}_{1} \cdots \mathrm{H}_{15}$ & 1.774 & 0.2630 & 0.0174 & 1.759 & 0.2821 & 0.0223 & 1.747 & 0.2835 & 0.0193 \\
\hline $\mathrm{O}_{2} \cdots \mathrm{H}_{11}$ & 1.755 & 0.2783 & 0.0196 & 1.745 & 0.2976 & 0.0239 & 1.733 & 0.2954 & 0.0218 \\
\hline $\mathrm{O}_{3} \cdots \mathrm{H}_{12}$ & 1.753 & 0.2788 & 0.0193 & 1.744 & 0.2956 & 0.0239 & 1.732 & 0.2971 & 0.0215 \\
\hline $\mathrm{O}_{4} \cdots \mathrm{H}_{13}$ & 1.752 & 0.2814 & 0.0196 & 1.742 & 0.3014 & 0.0241 & 1.730 & 0.2993 & 0.0218 \\
\hline $\begin{array}{l}\mathrm{O}_{5} \cdots \mathrm{H}_{14} \\
\text { (water) })_{6} \text { cage }\end{array}$ & 1.754 & 0.2791 & 0.0193 & 1.744 & 0.2988 & 0.0238 & 1.732 & 0.2982 & 0.0216 \\
\hline $\mathrm{O}_{1} \cdots \mathrm{H}_{17}$ & 1.707 & 0.2958 & 0.0288 & 1.698 & 0.3250 & 0.0342 & - & - & - \\
\hline $\mathrm{O}_{2} \cdots \mathrm{H}_{9}$ & 2.137 & 0.0522 & 0.0035 & 2.049 & 0.0746 & 0.0065 & & & \\
\hline $\mathrm{O}_{2} \cdots \mathrm{H}_{16}$ & 1.815 & 0.2153 & 0.0147 & 1.808 & 0.2222 & 0.0183 & & & \\
\hline $\mathrm{O}_{3} \cdots \mathrm{H}_{13}$ & 1.785 & 0.2450 & 0.0166 & 1.775 & 0.2606 & 0.0220 & & & \\
\hline $\mathrm{O}_{4} \cdots \mathrm{H}_{7}$ & 2.038 & 0.0830 & 0.0051 & 2.007 & 0.0917 & 0.0077 & & & \\
\hline $\mathrm{O}_{4} \cdots \mathrm{H}_{10}$ & 1.999 & 0.0959 & 0.0062 & 1.986 & 0.1007 & 0.0086 & & & \\
\hline $\mathrm{O}_{5} \cdots \mathrm{H}_{8}$ & 1.882 & 0.1689 & 0.0103 & 1.852 & 0.1831 & 0.0145 & & & \\
\hline $\begin{array}{l}\mathrm{O}_{6} \cdots \mathrm{H}_{11} \\
\text { (water) }{ }_{6} \text { pris }\end{array}$ & $\mathrm{m}^{1.832}$ & 0.2028 & 0.0155 & 1.816 & 0.2208 & 0.0202 & & & \\
\hline $\mathrm{O}_{1} \cdots \mathrm{H}_{9}$ & 2.030 & 0.0453 & 0.0052 & 1.974 & 0.0653 & 0.0087 & - & - & - \\
\hline $\mathrm{O}_{1} \cdots \mathrm{H}_{12}$ & 1.878 & 0.1518 & 0.0106 & 1.854 & 0.1705 & 0.0152 & & & \\
\hline $\mathrm{O}_{2} \cdots \mathrm{H}_{7}$ & 1.694 & 0.3053 & 0.0302 & 1.678 & 0.3460 & 0.0363 & & & \\
\hline $\mathrm{O}_{3} \cdots \mathrm{H}_{10}$ & 2.173 & 0.0275 & 0.0024 & 2.192 & 0.0290 & 0.0029 & & & \\
\hline $\mathrm{O}_{3} \cdots \mathrm{H}_{15}$ & 2.001 & 0.1064 & 0.0059 & 1.973 & 0.1131 & 0.0089 & & & \\
\hline $\mathrm{O}_{4} \cdots \mathrm{H}_{17}$ & 1.912 & 0.0789 & 0.0118 & 1.873 & 0.1126 & 0.0175 & & & \\
\hline $\mathrm{O}_{5} \cdots \mathrm{H}_{16}$ & 2.102 & 0.0406 & 0.0035 & 2.065 & 0.0528 & 0.0061 & & & \\
\hline $\mathrm{O}_{5} \cdots \mathrm{H}_{18}$ & 2.139 & 0.0215 & 0.0033 & 2.119 & 0.0304 & 0.0046 & & & \\
\hline $\mathrm{O}_{6} \cdots \mathrm{H}_{13}$ & 1.785 & 0.2470 & 0.0186 & 1.774 & 0.2630 & 0.0232 & & & \\
\hline
\end{tabular}

a If we try to reproduce the force constants reported in the literature, it is not uncommon to see a difference of \pm 0.001 and in some cases $\pm 0.002 \mathrm{mdyn} / \AA$. So the force constant values are accurate in the second decimal and uncertain at the third decimal, as numerical accuracy depends on the hardware and software used. The uncertainty in bond orders is large, especially in the case of hydrogen bonds. Therefore, reversals in the table for some compliance constants are not really a reversal.

\section{Conclusions}

The complete set of valence internal coordinates are the minimum required number of valence internal coordinates used to describe all the normal modes completely and should satisfy the symmetry requirement of the molecule. Suitable valence internal coordinates could be identified from the normal mode pictures obtained from the mass weighted cartesian coordinates. If chosen properly, they will have minimum mixing in the linear combination representing the normal modes. The stretching relaxed force constants of bonds are suitable to characterize the bond order of hydrogen bonds and other weak interactions when the normal coordinate analysis is done using a complete valence internal coordinate basis. In the electronic structure calculations, the chosen level of theory and the basis set should be reasonably good to get reliable relaxed force constants. 


\section{Acknowledgments}

We thank the Department of Science and Technology (DST), New Delhi for funding the computational facilities. We thank Professors N Sathyamurthy and S R Gadre for helpful discussions and the referee for reference 13 whose comments and questions were helpful in refining our ideas about the compliance constants.

\section{References}

1. Gold R, Dowling J M and Meister A G $1958 \mathrm{~J}$. Mol. Spectrosc. 29

2. Crawford Jr. B and Overend J 1964 J. Mol. Spectrosc. 12307

3. Chuang Y-Y and Trhuler D G 1998 J. Phys. Chem. A 102242

4. Brandhorst K and Grunenberg J 2007 Chem. Phys. Chem. 81151

5. Brandhorst K and Grunenberg J 2008 Chem. Soc. Rev. 371558

6. Brandhorst K and Grunenberg J 2010 J. Chem. Phys. 132 184101/1

7. Grunenberg J and Goldberg N $2000 \mathrm{~J}$. Am. Chem. Soc. 1226046 (see also the references in 4).

8. Grunenberg J 2004 J. Am. Chem. Soc. 12616310

9. Baker J 2006 J. Chem. Phys. 125 014103/1

10. Baker J and Pulay P 2006 J. Am. Chem. Soc. 12811324

11. Levine I N 1991 Quantum chemistry, 4th ed., New Jersey: Prentice Hall

12. Wu W, Gu J, Song J, Shaik S and Hilberty P C 2009 Angew. Chem. Int. Ed. 481407

13. Madhav M V and Manogaran S 2009 J. Chem. Phys. 131 174112/1

14. Julian M M 1998 J. Chem. Edu. 75497
15. Fernandez-Ramos A, Ellingson B A, Garrett B C and Truhler D G 2007 in Reviews in computational chemistry, Vol 23, Lipkowitz K B, Cundari T R, Boyd D B, (eds), New Jersey: Wiley-VCH

16. Berces A, Ziegler T and Fan L 1994 J. Phys. Chem. 98 1584

17. Wilson E B, Decius J C and Cross P C 1980 Molecular vibrations, New York: Dover Publications

18. Califano S 1976 Vibrational States, Wiley, London

19. McIntosh D F and Peterson M R 1989 Program UMAT, QCPE576, University of Indiana, Bloomington, IN 47405

20. Reed A E, Weinstock R B and Weinhold F 1985 J. Chem. Phys. 83735

21. Keutsch F N and Saykally R J 2001 Proc. Natl. Acad. Sci. USA 9810533

22. Su J T, Xu X and Goddard III W A 2004 J. Phys. Chem. A, 10810518

23. Frisch M J, Trucks G W, Schlegel H B, Scuseria G E, Robb M A, Cheeseman J R, Jr. Montgomery J A, Vreven T, Kudin K N, Burant J C, Millam J M, Iyengar S S, Tomasi J, Barone V, Mennucci B, Cossi M, Scalmani G, Rega N, Petersson G A, Nakatsuji H, Hada M, Ehara M, Toyota K, Fukuda R, Hasegawa J, Ishida M, Nakajima T, Honda Y, Kitao O, Nakai H, Klene M, Li X, Knox J E, Hratchian H P, Cross J B, Adamo C, Jaramillo J, Gomperts R, Stratmann R E, Yazyev O, Austin A J, Cammi R, Pomelli C, Ochterski J W, Ayala P Y, Morokuma K, Voth G A, Salvador P, Dannenberg J J, Zakrzewski V G, Dapprich, Daniels A D, Strain M C, Farkas O, Malick D K, Rabuck A D, Raghavachari K, Foresman J B, Ortiz J V, Cui Q, Baboul A G, Clifford S, Cioslowski J, Stefanov B B, Liu G, Liashenko A, Piskorz P, Komaromi, Martin R L, Fox D J, Keith T, Al-Laham M A, Peng C Y, Nanayakkara A, Challacombe M, Gill P M W, Johnson B, Chen W, Wong M W, Gonzalez M W and Pople J A, GAUSSIAN 03, revision B.03, 2003 Pittsburgh, PA: Gaussian Inc 